\title{
O MÉTODO DA EMANCIPAÇÃO CHEGA AO NOVO MUNDO: O ENSINO UNIVERSAL DE JACOTOT NO BRASIL (1840-1848)
}

\begin{abstract}
Crislaine Santana $\mathrm{Cruz}^{1}$ Silvana Aparecida Bretas ${ }^{2}$

\section{Resumo}

O presente estudo divulga os resultados da dissertação intitulada: "Caridade sem limites. Sciência sem privillegios": o Ensino Universal de Jacotot por Benoît Mure no Brasil (1840-1848). A ideia de novo mundo para se referir ao recém descoberto continente americano permeou o pensamento de estrangeiros europeus curiosos por conhecer o Brasil no século XIX. Imaginar uma terra onde se podia criar uma sociedade diferente, tendo como base um velho mundo viciado e em que já não era possível acreditar na igualdade entre os homens, de certo, motivou a vinda de muitos imigrantes para esta nova terra, com ideias de criar aqui uma sociedade nova e sem os vícios do antigo continente. Benoît Jules Mure representa bem esse estrangeiro animado pela possibilidade de um novo começo numa nova terra. $\mathrm{O}$ nosso objetivo é o de compreender as ações e modos de divulgação empregados por Benoît Jules Mure para promover as ideias do Método do Ensino Universal no Brasil. O estudo se baseia em autores como: Rancière (2013); Sirinelli (2003); Faria Filho (2011), entre outros. Destaca-se que Mure atuou em diversas frentes na divulgação do Método, desde publicações nos periódicos da época, até sua aplicação na escola de Homeopatia.
\end{abstract}

Palavras-chaves: Ensino universal. Joseph-Jacotot. Benoît Mure. Século XIX. Igualdade.

\section{THE METHOD OF EMANCIPATION ARRIVES TO THE NEW WORLD: JACOTOT'S UNIVERSAL TEACHING IN BRAZIL (1840-1848)}

\begin{abstract}
The present study discloses the results of the dissertation entitled: "charity without limits. Science without Privileges ": Jacotot's Universal Teaching by Benoît Mure in Brazil (18401848). The idea of a new world to refer to the newly discovered American continent permeated the thinking of curious European foreigners to know Brazil in the nineteenth century. Imagining a land where one could create a different society, based on an old world addicted and where it was no longer possible to believe in equality between men, certainly motivated the arrival of many immigrants to this new land with ideas to create here a new society and without the vices of the old continent. Benoît Jules Mure represents this foreigner excited by the possibility of a new beginning in a new land. Our goal in this section is to understand the actions and modes of disclosure employed by Benoît Jules Mure to promote the ideas of the Universal Teaching Method in Brazil. The study is based on authors such as: Rancière (2013); Sirinelli (2003); Faria Filho (2011), among others. It
\end{abstract}


is noteworthy that Mure acted on several fronts in the dissemination of the Method, from publications in periodicals of the time, until its application in the homeopathy school.

Keywords: Universal teaching. Joseph-Jacotot. Benoît Mure. XIX century. Equality.

\title{
EL MÉTODO DE LA EMANCIPACIÓN LLEGA AL NUEVO MUNDO: LA ENSEÑANZA UNIVERSAL DE JACOTOT EN BRASIL (1840-1848)
}

\begin{abstract}
Resumen
El presente estudio divulga los resultados de la disertación titulada: "caridad sin límites. Science sin privilegios ": la Enseñanza Universal de Jacotot por Benoît Mure en Brasil (1840-1848). La idea de nuevo mundo para referirse al recién descubierto continente americano impregnó el pensamiento de extranjeros europeos curiosos por conocer a Brasil en el siglo XIX. Imaginar una tierra donde se podía crear una sociedad diferente, teniendo como base un viejo mundo viciado y en que ya no era posible creer en la igualdad entre los hombres, de cierto, motivó la venida de muchos inmigrantes a esta nueva tierra, con ideas de crear aquí una sociedad nueva y sin los vicios del antiguo continente. Benoît Jules Mure representa bien a este extranjero animado por la posibilidad de un nuevo comienzo en una nueva tierra. Nuestro objetivo en esta sección es el de comprender las acciones y modos de divulgación empleados por Benoît Jules Mure para promover las ideas del Método de la Enseñanza Universal en Brasil. El estudio se basa en autores como: Rancière (2013); Sirinelli (2003); Faria Hijo (2011), entre otros. Se destaca que Mure actuó en diversos frentes en la divulgación del Método, desde publicaciones en los periódicos de la época, hasta su aplicación en la escuela de Homeopatía.
\end{abstract}

Palabras claves: Enseñanza universal. Joseph-Jacotot. Benoît Mure. Siglo XIX. La igualdad.

Joseph Jacotot foi um consciencioso professor e leitor de literatura francesa na Universidade de Louvain quem em 1818 experimentou uma aventura intelectual que se tornou a base fundamental de um método de ensino, baseado na emancipação intelectual que defendia a ideia de igualdade entre as inteligências das pessoas. Esse método ficou conhecido como Ensino Universal, ou, Método Jacotot e conviveu com diversas propostas pedagógicas quando a sociedade francesa lançava os alicerces da educação institucionalizada.

As ideias propagadas por Jacotot e seu método da igualdade ganharam notoriedade expressiva em grande parte da Europa e em outras regiões do mundo. Viajaram, inclusive, até o Brasil, trazidas por franceses que aqui residiram, entre eles, o intelectual Benoît Jules Mure. Contudo, por conta de sua profissão como médico homeopata e seu embasamento 
Artigo

doi: $10.20396 /$ rho.v18i4.8653536

socialista, Mure faz uma interpretação das ideias de Jacotot que tomarão conotações próprias em território brasileiro.

Benoît Mure foi um médico, engenheiro, inventor, editor, pensador político e poeta. Acreditava que um homem pudesse ser sapateiro e intelectual ao mesmo tempo. Pretendeu realizar uma dupla reforma no Brasil, médica e social, por acreditar ser possível a construção de uma sociedade harmoniosa em que finalmente se atingiria a igualdade entre os homens.

A ideia de novo mundo atraiu a Mure até o Brasil. De fato, o uso deste termo para se referir ao recém descoberto continente americano permeou o pensamento de estrangeiros europeus desde pelo menos o século $\mathrm{XV}$, mas ainda representava um uso em voga no século XIX. Imaginar uma terra onde se podia criar uma sociedade diferente, tendo como base um velho mundo em que já não era possível acreditar na igualdade entre os homens, de certo, motivou a vinda de muitos imigrantes para esta nova terra. Benoît Jules Mure representa bem esse estrangeiro, por um lado, descontente com sua terra de origem e, por outro, animado pela possibilidade de um novo começo numa nova terra. O objetivo desse trabalho é o de compreender as ações e modos de divulgação empregados por Benoît Jules Mure para promover o Método do Ensino Universal no Brasil, país que havia escolhido como local de fermentação de seus ideais.

\section{A INSERÇÃO DE MURE NA SOCIEDADE DA CAPITAL DO NOVO MUNDO}

A sociedade carioca que Mure conhecera tentava adaptar-se aos padrões culturais europeus de civilização, importando especialmente da Inglaterra e França desde obras literárias até os hábitos mais cotidianos. Vale lembrar ainda que o Rio de Janeiro assumia um lugar de destaque no cenário brasileiro, era a capital do império, por isso seus padrões de desenvolvimento se distinguiam da maior parte do país, que era ainda rural. Porém, mesmo reproduzindo determinadas características do velho mundo, o Rio de Janeiro estava longe de ser confundido com uma cidade europeia. Especialmente a presença maciça de negros e mestiços, pelas ruas da capital, fazia com que os estrangeiros que aqui chegavam logo notassem as diferenças entre o novo e o velho mundo.

Hermann Burmeister (1980), um viajante alemão que esteve no Rio de Janeiro em 1850, escreveu em seu livro 'Viagens ao Brasil através das províncias do Rio de Janeiro e Minas Gerais': "O Rio de Janeiro possui caráter inteiramente europeu e seria de todo semelhante às primeiras cidades da Europa do sul, não fosse aquele grande número de rostos pretos, morenos e amarelos que logo lembra o exotismo ao visitante [...]". (BURMEISTER, 1980, p. 59). Para Barra (2015, p. 795) essa condição dava ao Rio de Janeiro um caráter de duas cidades sobrepostas, aquela que exprimia a "sociabilidade da 
Artigo

doi: $10.20396 /$ rho.v18i4.8653536

Corte", com a criação de novos espaços-símbolo de civilização e a adoção de comportamentos civilizados, e aquela que esboçava a "sociabilidade da Cidade", que se caracterizava "[...] nos hábitos da grande massa de negros e mestiços, homens livres e pobres que povoavam as ruas do Rio de Janeiro."

A grande quantidade de homens e mulheres negras estava constantemente nos espaços urbanos, como descreve Burmeister (1980, p. 73): "Esses carregadores de café não só se ouvem e vêem todos os dias nas ruas do Rio, como também se pressentem pelo olfato [...]". Logo em seguida acrescenta: "Não é menor, na rua, o número de negras. Costumam elas parar à sombra das casas, oferecendo à venda quitutes ou, mais frequentemente, frutas e legumes dispostos em grandes cestas rasas ou bandejas, que carregam na cabeça [...]". A presença dessa população nos espaços urbanos e de sociabilidade costumava incomodar, como enfatiza Barra (2015, p. 800):

A rua era o espaço de sociabilidade por excelência desse vasto contingente populacional. Nas ruas, praças e chafarizes, onde por vezes o grande concurso gerava desordens, eles trabalhavam e levavam sua vida, exercendo as funções de carregadores, remadores, vendedores ambulantes, barbeiros e cirurgiões, carregando água, fazendo compras para seus senhores ou trabalhando nas obras públicas. A sua circulação não estava restrita a determinadas áreas da cidade. Pelo contrário, em geral eles estavam mais próximos da Corte do que se gostaria, concentrando-se nas áreas de grande atividade comercial (a Alfândega, a Rua Direita, o Largo do Paço).

O Rio de Janeiro da primeira metade do século XIX, não poderia prescindir da presença dos negros, pois era justamente do trabalhar de mãos escravas que se erguiam os grandes símbolos de civilização, em uma sociedade que condenava a presença de negros nos espaços públicos em que circulava as pessoas abastadas, mas que se sustentava na exploração desses mesmos negros.

O sociólogo brasileiro Darcy Ribeiro (1975), ao analisar a cultura brasileira, argumenta que esta seria um arquipélago cultural devido sua rica formação, fruto que é de diferentes matrizes indígenas, africanas e européias. Estas entraram em conjunção compondo através da interação de seus elementos, células culturais novas que se fundiram numa proto-etnia complexa formando um tecido cultural multifacetado por ocasião de vários fatores como: os diferentes ambientes ecológicos que compõem o vasto território brasileiro, o exercício de atividades produtivas variadas, a agregação de novos elementos culturais devidos a sua constante criatividade ou adotados de contextos culturais diferentes, além da incorporação de novos contingentes humanos.

Porém, ao tempo em que é tão rico culturalmente, o Brasil, nos diferentes momentos de sua história, sofreu a ação de forças homogeneizadoras que integraram as diversas variações culturais dentro de um padrão básico compartilhado. E sua origem colonial concorreu fatalmente para isso, Segundo Ribeiro (1975, p. 155): 


\begin{abstract}
Operaram como homogeneizadoras, fundamentalmente, as instituições sócioculturais européias que, organizando a sociedade nascente como uma dependência colonial, a conformaram dentro dos padrões culturais lusitanos. A sociedade e a cultura brasileira nascem, assim, como um fruto ultramarino de uma tradição cultural romântica, muitas vezes transfigurada e que aqui se transfiguraria uma vez mais para dar lugar a uma nova etnia nacional. Esta surge, portanto, como produto de uma civilização agrária, urbana e mercantil que, mesmo nos seus primeiros núcleos ainda larvares, era já uma formação evolutiva mais alta que as etnias tribais indígenas e africanas.
\end{abstract}

Esse caráter filial e servil a uma metrópole externa, a portuguesa, fez com que a nascente civilização brasileira se desenvolvesse por meio do trabalho do seu povo, mas não para servir ao seu povo, presa que estava a um anseio de servir a interesses externos, a princípio, os portugueses. Então, o Brasil desenvolveu-se como nação, por meio de múltiplas e dispersas implantações, mas também unificadas através de um processo de dominação que se arrastou, ou se arrasta, ao longo dos séculos.

Nesse processo, explica Ribeiro (1975), a unificação se afirma sempre através do evento de três ordens de diferenciação. A primeira ordem de diferenciação é a temporal, que corresponde as sucessivas configurações históricas e aos esforços correlativos de integração nos processos civilizatórios que as afetaram; a segunda ordem refere-se as contingências sociais, “[...] como subculturas correspondentes, por um lado, à afeição rural-urbana que assumiam e, pelo outro, à estratificação de classes (senhorial, servil, popular) [...]" (RIBEIRO, 1975, p. 155); a terceira ordem de diferenciação é a regional, diz respeito as diferenças de adaptação ecológica que se moldaram como distintas áreas culturais. Para Ribeiro (1975), esses três fatores de diferenciação contribuem para a riqueza cultural do Brasil, mas implicam também situações de defasagem, marginalidade e de dependência sócio-cultural, cada um com seus efeitos característicos.

No primeiro caso, as contingências temporais produzem "[...] efeitos diferenciais dos processos de mudança sobre os diversos setores, em virtude dos quais alguns deles se modernizam e outros se tornam arcaicos." (RIBEIRO, 1975, p. 156). No segundo caso, as contingências sociais geram oposições entre os diversos estratos da sociedade nacional que, apesar de experimentar uma forte miscigenação racial e uma uniformização cultural, “[...] se cristalizam como uma rígida estratificação sócio-racial de castas, cujos estatamentos se vêem uns aos outros como entidades distintas e se hostilizam reciprocamente, criando um ambiente marcado por fortes tensões." (RIBEIRO, 1975, p. 156). As consequências das contingências regionais são marcadamente, as diferenças de desenvolvimento das diversas regiões do Brasil que ao intensificar sucessivamente diferentes áreas de produção, tornando-as verdadeiros núcleos polarizadores da vida econômica, terminam por provocar efeitos agudos de colonização interna.

A cultura brasileira desenvolveu assim, um caráter espúrio decorrente da sua formação colonial escravista e servil aos interesses do mercado europeu. A classe 
Artigo

doi: $10.20396 /$ rho.v18i4.8653536

dominante brasileira foi, desde sua formação, chamada a cumprir um papel gerencial a favor de interesses estrangeiros, não chegando a se constituir “[...] um estrato senhorial e erudito de uma sociedade autônoma, mas uma representação local, alienada, de outra sociedade cuja cultura buscava mimetizar." (RIBEIRO, 1975, p. 157). Essa classe dominante passa então a cumprir um papel que apresenta quatro facetas manipuláveis, como num jogo de xadrez em que se lança mão de várias estratégias, ela é gerencial no nível econômico-produtivo, ordenadora no nível político-social, renovadora no plano tecnológico-científico e, doutrinária no nível ideológico.

A classe dominante branca do século XIX preocupava-se em assemelhar-se culturalmente a Europa como forma de salientar a sua branquidade e, por consequência a sua superioridade racial junto ao restante da população brasileira:

[...] E conseguia simular, razoavelmente, estas indentificações nos modos de morar, de vestir, de comer, de educar-se, de rezar, de casar, de morrer, etc. Só a ação diferenciadora dos fatores ecológicos e do contexto humano em que vivia é que, a seu pesar, a tornavam irremediavelmente brasileira nestas mesmas coisas. (RIBEIRO, 1975, p. 158).

O empenho demonstrado por essa classe, para simular uma identificação com o continente Europeu era notado inclusive pelos viajantes estrangeiros que aqui chegavam. Se tomarmos como exemplo as modas lançadas em Paris, nota-se que não demoravam muito para ser logo encontradas por aqui, porém as diferenças entre as duas culturas persistiam, como observado por Burmeister (1980, p. 70):

Os elementos da população branca não se distinguem mais, pelo seu aspecto externo, do europeu, pois observam tão rigorosamente a moda em vigor como os habitantes de uma capital do Velho Mundo [...] Nas mulheres das classes mais elevadas, notei somente trajes de acordo com a moda em vigor. Contudo persiste a diferença entre a gente da terra e os estrangeiros, mantida mais pelos últimos do que pelos elementos daquela [...].

Junto a essa necessidade de identificação com tudo o que era estrangeiro existia, por parte da classe dominante branca, a repulsa a tudo o que era nacional e popular. $\mathrm{O}$ que gerava paralelamente uma busca excessiva para identifica-se com a cultura europeia, por um lado e; a negação de sua própria identidade local, por outro lado. Para Ribeiro (1975, p. 159), a alienação passou a ser, por essas circunstâncias, condição mesma da classe dominante brasileira: "[...] inconformada com o seu mundo atrasado, que só mediocremente conseguia imitar o estrangeiro, e cega para os valores de sua terra e de sua gente $[\ldots] "$.

A intelectualidade brasileira que se formou com o passar dos anos, não fugia a regra geral, uma vez que era constituía, na sua maior parte, pela classe dominante branca, formou-se através do transplante de ideias e valores alheios. O primeiro núcleo erudito da nascente civilização era o clero, a um só tempo, "[...] cultor das letras e protetor das artes". 
Artigo

doi: $10.20396 /$ rho.v18i4.8653536

Após as décadas que se seguiram a independência do país, esse quadro foi-se alterando. A elite clerical desaparece, dando espaço a "coorte de bacharéis letrados [...]" (RIBEIRO, 1975, p. 160) que dominariam a setor intelectual a partir da primeira metade do século XIX.

Essa nova intelectualidade passa a assumir como missão promover o avanço da civilização no país e exprimiam suas ideias por meio da imprensa, que nasce com a vinda da Família Real portuguesa em 1808, mas começa a se fortalecer e ganhar destaque a partir do Segundo Reinado, com o apoio do Imperador D. Pedro II, como enfatiza, Lima (2008, p. 4) ao se referir ao Monarca:

Comumente descrito pelos seus contemporâneos como um amante das letras e
das ciências, o monarca Pedro II foi uma personagem de destaque nesse cenário
e desempenhou o papel de grande incentivador da elevada missão de tornar o
país um exemplo de progresso e civilização. Além de presidir sempre que
possível as sessões do Instituto Histórico e Geográfico Brasileiro, Pedro II
estimulou o surgimento e proliferação dos periódicos.

Dessa forma, houve na primeira metade do século XIX a proliferação de periódicos, assim como associações e sociedades formadas por intelectuais na corte do Rio de Janeiro. Havia certa homogeneidade na elite intelectual oitocentista, que era em maior parte formada por profissionais liberais, como advogados, jornalistas, engenheiros, médicos, entre outros. Essa homogeneidade se explica desde sua formação acadêmica, comumente realizada na Europa, até a posição social de destaque que assumiam, já que muitos ocuparam cargos políticos, por isso, suas ideias e posicionamentos raramente divergiam. (LIMA, 2008).

Benoît Mure, um estrangeiro que se inseriu entre os intelectuais brasileiros da primeira metade do século XIX, especialmente entre os doutores da medicina oficial do império, que ocupavam várias posições de destaque, fosse como membros do Instituto Histórico e Geográfico Brasileiro (MALEVAL, 2011), fosse como lentes da Academia de Medicina, ou ainda ocupante de cargos públicos. Durante a década em que esteve no Rio de Janeiro, Mure desestabilizou o meio intelectual carioca. A inserção de suas ideias, sobre a própria concepção de medicina e de ciência, sua visão socialista e, como não deixou de ser, seu ideal educativo, não ocorreu sem que houvesse resistência por parte da maioria dos doutores da época. Porém nem toda a resistência impediu que suas ideias, médicas, sociais e educativas, germinassem em território brasileiro.

Se tratando das ideias educativas que Mure alimentava por influencia da teoria de Jacotot, vale ressaltar que o intelectual não foi o único a espalhar a semente do Ensino Universal em território brasileiro, não seria difícil a um leitor do 'Jornal do Commercio do Rio de Janeiro' encontrar anúncios de traduções de obras de Jacotot, além de cursos de língua francesa através de seu método, como exemplificam os recortes a seguir: 


\begin{abstract}
- Sciencia de guarda livros ensinada em vinte huma lições, e sem mestre, ou tratado completo da escripturação de livros em partidas simples e dobradas, posto ao alcance das pessoas que não tem desta sciencia idéa alguma; por $\mathbf{J}$. Jacotot professor da escripturação universal, traduzida pelo Dr. J Candido de Deos e Silva, 1 vol. em 4. ${ }^{\circ}$; vende-se por 6 réis, na loja de livros de Albino Jordao rua do Ouvidor n. 121, entre as dos Ourives e Latoeiros, casa do livro azul. (JORNAL DO COMMERCIO, 1841, p. 3, grifo nosso).
\end{abstract}

\title{
CURSO THEORICO PRATICO DE LINGUA FRANCEZA
}

Por um novo methodo, extrahiado do que ha mais proveitoso nos methodos de Lancaster, Jacotot e Pestalozzi, pelo qual póde-se em muito pouco tempo aprender a traduzir, escrever, e até mesmo a fallar o dito idioma. As lições deste curso, dadas por Mr. J. J. Gonnet, terão lugar tres vezes na semana, das 6 ás 7 1/2 horas da tarde, na sala do primeiro andar da casa da rua do Ouvidor n. 130 B, onde desde já se podem inscrever as pessoas que queirão aproveitar das ditas, pelo preço da 4\$ 000 rs. Mensais. (JORNAL DO COMMERCIO, 1846b, p. 4, grifo nosso).

\section{LINGUA FRANCESA}

O doutor em leis Huet, recém-chegado a esta corte, lecciona as linguas franceza e latina, assim como história, geografia, esfera, mathematicas, escripturação commercial e as mesmas leis commerciaes, pelo methodo Jacotot; na rua da Alfandega n. 278. (JORNAL DO COMMERCIO, 1848, p. 3, grifo nosso).

Percebemos, ao encontrar esses anúncios que, a divulgação das ideias de Jacotot no Brasil do século XIX, estava para além da atuação de Benoît Mure, que era mais um de seus divulgadores. Esta se deu por intermédio de indivíduos e/ou grupos singulares e independentes entre si, cada um guardando sua experiência com o método do Ensino Universal, que fora proposto na França, por Jacotot. Essa divulgação era feita então, de maneira pontual e diversa. Nosso foco de análise, entretanto, dirige o nosso olhar as ações e modos de divulgação engendrados por Benoît Mure na divulgação desse método, no período em que esteve no Brasil. Como o intelectual atuou em diversas frentes a favor da divulgação do Ensino Universal, dividimos suas ações em duas fases.

\section{MURE NO JORNAL DO COMMERCIO: PRIMEIRA FASE DA PROPAGANDA A FAVOR DO ENSINO UNIVERSAL}

O ano de 1840 marcaria acontecimentos importantes para a vida de Mure, sua vinda ao Brasil, país até então desconhecido, e a morte de Joseph Jacotot em Paris, segundo o próprio Mure, seu mestre. Desde a sua chegada, Mure fizera divulgação do Ensino Universal. Para nós esse empenho esteve ligado a sua crença na eficácia do método de Jacotot, especialmente para os pais que não podiam manter seus filhos na escola. Como defende Rancière (2013), o Ensino Universal deveria ser divulgado a todos, mas em especial aos "pobres", pois eram os que mais sofriam com a teoria da desigualdade entre as inteligências, salienta o filósofo: 


\title{
Revista HIIS'TNIDBR On-line
}

É, pois preciso anunciar o Ensino Universal a todos. Antes de tudo, aos pobres, sem qualquer dúvida: eles não têm outro meio de se instruírem, não podem pagar explicadores particulares, nem passar longos anos nos bancos escolares. Acima de tudo, é sobre eles que pesa mais fortemente o preconceito da desigualdade das inteligências. São eles que devem ser reerguidos de sua posição de humilhação. O Ensino Universal é o método dos pobres. (RANCIÈRE, 2013, p. 147).

Mure desembarcou aqui, em novembro de 1840 e logo após a sua chegada, em dezembro desse mesmo ano, publicou uma nota em homenagem a Jacotot no "Jornal do Commercio do Rio de Janeiro", oferecendo-se inclusive para explicar o seu método a quem se interessasse.

\begin{abstract}
METHODO JACOTOT
Quando morrem os homens illustres he que se conhece quanto valem. Assim aconteceu com Jacotot, que depois de huma vida toda consagrada ao trabalho e a beneficencia, acaba de morrer com admiravel coragem e presença de espirito. $<<$ Sou o principio da vontade na humanidade, disse-nos em seus ultimos momentos; mas vós, que agora sois emancipados, podeis tudo o que eu podia, e deveis faze-lo. >>

Animado por essas palavras, e achando-meencarregado pela Sociedade de Emancipação Intellectual de Paris de ajudar nesta corte os esforços dos amigos do ensino universal, rogo a todos aquelles que nelle se interessão, e que até hoje não me são conhecidos, queirão vir entender-se comigo sobre os meios de que se deve lançar mão para conseguir-se a propagação dos princípios panecasticos. Dirijao-se ao hotel da Europa. DR. MURE. (JORNAL DO COMMERCIO, 1840a, p. 4).
\end{abstract}

Como vemos, Mure demonstra seu interesse em divulgar o método de Jacotot desde o primeiro momento de sua chegada, indicando até mesmo o local de sua hospedagem a fim de contribuir para a propagação do Ensino Universal, declarando fazê-lo em nome da 'Sociedade de Emancipação Intelectual de Paris'. Jacques Rancière (2013) refere-se a uma 'Sociedade de Filosofia Panecástica', criada por fiéis partidários de Jacotot na França, talvez a mesma instituição citada por Mure. No plano do falanstério que apresenta no Jornal do Commercio, Mure, destaca como uma das vantagens de sua implantação, a criação de um novo sistema de educação e faz críticas ao ensino clássico que vigorava no país responsável pela formação dos bacharéis em Direito do doutores em Medicina:

Outra vantagem dessa medida he que a administração da commum, encarregada da vigilancia desses fundos, estabelecerá hum bom systema de educação unitaria, que he hum dos objetos mais desejaveis e uteis. Pouco trataremos de formar sabios, mas sim obreiros e executores: parece a quem vê as sociedades actuaes com suas pedantescas universidades, em que só se occupão com línguas e usos da antiguidade, que o estudo do grego e do latim pode supprir a quaesquer outros, e ao ver todas as familias que o podem mandar seus filhos às faculdades de direito e de medicina; dir-se-hia que o homem social no século XIX nasceu para estar doente ou ter demandas [...]. (JORNAL DO COMMERCIO, 1840b, p. 2).

Para Mure, a supervalorização da formação humanística, baseada na filosofia e na retórica, que era tão almejada pela classe dominante (FERREIRA JUNIORR, 2010), 
tornava o estudo odioso por não corresponder à escolha natural do estudante. Afinal nem todos nasceram para tornarem-se médicos ou advogados. Na educação baseada no método de Jacotot, ao contrário, os meninos teriam liberdade para escolher que profissão seguir:

\begin{abstract}
[...] Ao demais, inteira liberdade será deixada aos meninos, e a commum sociedade olhará como dever sagrado desenvolver todas as aptidões cujo precioso germen houver a natureza depositado nessas fracas creaturas.

Assim para o futuro cada huma das funções de nossa ordem social será preenchida por quem fôr capaz de desempenha-la. Não teremos como hoje medicos que a natureza destinou para sapateiros, e pedreiros que poderião ter sido Raphaeis. O benefico methodo Jacotot, pelo qual qualquer ignorante pode sem custo ensinar aquilo que não sabe, achará aqui sua mais bela aplicação. Possa em breve brilhar o dia em que as famílias opulentas deste paiz, que mandão seus filhos a Europa, para lá receberem os vicios e as preocupações de nossas velhas sociedades, os mandem aos nossos estabelecimentos, onde em poucas semanas aprenderão o que levão 10 annos a aprender em nossos colégios! (JORNAL DO COMMERCIO, 1840b, p. 2).
\end{abstract}

Mure também, pensava em uma união entre indústria e educação para o trabalho, o que segundo Ferreira Junior (2010), não estava no pensamento da elite brasileira do Império, que inserida no contexto de uma sociedade agrária e escravocrata não via uma relação direta científica entre educação e o trabalho produtivo. Para o pesquisador estabeleceu-se no Brasil uma dicotomia inconciliável entre as chamadas artes liberais (educação para a política) e as artes mecânicas (instrução para o trabalho), sendo que na relação escravista, nem se quer existia uma educação voltada para o trabalho, uma vez que os escravos eram simplesmente adestrados apara executar tarefas em que utilizavam a força bruta. Já a educação voltada para a política consistia em obter o título de bacharel, exercer a profissão até possuir capital necessário para se comprar uma fazenda, desempenhar uma função política, ser reconhecido como um distinto membro das elites agrárias, para poder finalmente, desfrutar do ócio; uma garantia para poucos e, que era proporcionada pelo trabalho escravo.

Assim, a exploração das potencialidades tecnológicas encontra-se associado a outros fatores, como o modo de organização das relações de produção, pelo caráter da estrutura de poder e, por fatores ideológicos. (RIBEIRO, 1975). O Brasil ainda era um país agrário e o processo de industrialização que ocorria a pleno vapor nas potencias industriais europeias, era aqui muito incipiente. O projeto falansteriano de Mure foi recebido com entusiasmo pelo governo imperial e grandes proprietários, justamente por representar para estes uma possibilidade de industrialização e de civilização para o país. Pensar numa educação integrada a indústria era, portanto, uma novidade para o Brasil, e Mure seguia na sua exposição:

Haverá tanta alegria, actividade e ventura entre nossos meninos, quanto he hoje sua preguiça, quanto seu aborrecimento. Utilisando-os nos trabalhos da industria, instrui-los-hemos em seus methodos. He hum erro considerar os meninos como inuteis e indolentes: se soubéssemos aproveitar essa actividade irresistível de que dão exemplo seus brinquedos, veriamos quantos recursos póde a industria tirar 


\begin{abstract}
de seu concurso. Seria para isso preciso que a tornassem facil e agradavel para elles. O ensino das artes e officios he hoje quasi tão estupido e embrutecedor como o dos collegios. He pelo attractivo, he pelo discretos emprego de todas as vocações naturaes, que nossos filhos serão serão convidados para o trabalho. Teremos o cuidado de não exhaurir sua boa vontade com mui prolongadas sessões. Curtas e variadas, suas occupações serão prazeres, e mais terão nossos mestres de moderar do que incitar seu zelo. A combinação das artes agricolas e manufactureiras deixará intermeiar essas occupações do modo mais inciante, e os meninos não serão os unicos que aproveitem essa feliz alliança. Meninos por esse modo educados serão não só mais alegres e venturosos do que os nossos, serão tambem muito mais uteis, e começarão mui cedo a prestar serviços reaes aos obreiros e lavradores que lhes tiverem dado suas primeiras lições. Teriamos que dar exemplos praticos da hypothese que hoje estabelecemos, os elementos do vasto systema de que damos conta existem por toda parte no velho mundo: quem pois duvidaria da facillidade do bom exito de nossa empresa, quando todas essas peças separadas de huma grande machina, reunidas, emfim, se prestarem hum mutuo apoio e se engrasilharem humas nas outras. (JORNAL DO COMMERCIO, 1840b, p. 2).
\end{abstract}

Pudemos notar que nesse início da divulgação do Ensino Universal, Mure estava sozinho e suas publicações a respeito do método eram poucas, ressaltando que se dava juntamente com a divulgação da homeopatia e do socialismo. Com o passar dos anos e, na medida em que Mure foi ganhando espaço essas publicações passaram a serem publicadas com maior intensidade, não só por ele, mas também por seus colaboradores, assim como por opositores que criticavam as ideias de Mure no 'Jornal do Commercio'.

Até 1840, Mure era um completo desconhecido dentro do campo médico brasileiro e chegou com propostas inovadoras, não só para a medicina e, assim que aportou na capital do império com o intuito de fundar seu falanstério, e antes mesmo de rumar para Santa Catarina, consegue angariar no Rio de Janeiro um adepto a causa homeopática, que foi o Dr. A J. Souto Amaral, já mencionado e segundo Galhardo (1928, p. 286) um renomado cirurgião, depois de algumas visitas a doentes "pobres". Logo em janeiro de 1841, Mure converte também o Dr. Thomaz da Silveira, médico que atuava em Santa Catarina. Ainda no mesmo ano ganhou a simpatia do Dr. Lisboa, médico português e depois foi a vez do Dr. José da Gama e Castro que era redator do 'Jornal do Commercio'. Um a um Mure foi colhendo adeptos e engrossando cada vez mais a fileira dos que combatiam pela causa homeopática. E dentre os que simpatizavam com o homeopata francês estavam, inclusive integrando a diretoria do Instituto Homeopático, nomes de peso da sociedade carioca como o Visconde de Olinda, Tranfo Vianne, Lacerda, Perdigão Malheiros e Lima e Silva. (JANOT, 1999).

Na medida em que foi angariando simpatizantes, a maioria médicos, à homeopatia. Mure procurou também convencê-los de seus ideais a respeito da educação, e nesse domínio era o Ensino Universal por ele defendido como a melhor resposta para os problemas educacionais. O médico homeopata foi tecendo paulatinamente uma rede de afetividade em torno de si, da qual nos fala Sirinelli (2003), ao afirmar que as estruturas de 
sociabilidade que se traduzem tanto na atração e a amizade, como na ruptura, na rivalidade, na briga etc., exerce, por vezes, papel decisivo no estudo de intelectuais. Dentre os médicos que Mure conseguiu convencer também ao Ensino Universal, destaca-se o Dr. João Vicente Martins, que se tornou seu maior apoiador e incentivador a partir de 1843. Este médico chegou, inclusive a escrever uma obra intitulada 'Horas vagas' na qual aborda as teorias dos pensadores que seu amigo e mestre Mure o havia apresentado, entre eles Jacotot e, a divulga no 'Jornal do Commercio no ano de 1846':

\begin{abstract}
Nesta obra, que sahirá em quadernos, tratarei, no estylo romantico, e servindome sempre de factos historicos, $1^{\circ}$, de Jacotot e seu methodo; $2^{\circ}$, de Hahnemann e suas doutrinas; $3^{\circ}$, de Fourrier e suas teorias; $4^{\circ}$, de Mesmer e o magnetismo; e em toda essa obra minhas opiniões irão tão claras, tão francas, quanto o permite o estylo em que eu souber escrever. Sei muito bem a quanto me exponho, mas sei que é meu dever antes de todos ser verdadeiro, e sê-lo tão claramente que me comprehendão bem. - Metade do producto liquido desta obra ha de ser entregue ao Sr. thesoureiro da Imperial Sociedade Amante da Instrução, para ser aplplicado às despesas do novo collegio de órfãos. Não creio que a repugnancia em aceitar minha offerta vá até ao instante de ser ella realisada. Talvez que até mesmo o silencio que tem respondido a meu offerecimento encontre muito justificados motivos.... Seja como fôr, eu cumpro a minha obrigação. Que meus consocios, agora auxiliando meu esforço, cumprão igualmente a sua, e não sirvão a má vontade de alguém [...]. (JORNAL DO COMMERCIO, 1846c, p. 2).
\end{abstract}

A referida obra de João Vicente Martins, teve seus rendimentos consagrados pelo autor a um colégio de órfãos recém-criado na corte do Rio de Janeiro e que tinha por nome 'Imperial Sociedade Amante da Instrução'. Segundo Martins o colégio havia lhe pedido uma "esmola" e o médico prontamente se disponibilizou em ajudar, porém ao que parece, sua ajuda teria sido recusada posteriormente, por ser ele declaradamente adepto da homeopatia. Ainda assim, o médico insistiu em dar a sua contribuição.

Fatos como este não eram raros no cotidiano de médicos homeopatas no início do século XIX. O próprio Mure foi expulso do Instituto Histórico e Geográfico Brasileiro em 1847, constituído por homens proeminentes da sociedade carioca, muitos destes, médicos alopatas, que não admitiram as colocações que Mure fizera a respeito da morte do filho primogênito do Imperador, D. Afonso ${ }^{3}$. O homeopata, ao escrever uma peça, a ser publicada na Revista do Instituto sobre a dolorosa tragédia, fez supor que se o príncipe tivesse recebido um tratamento homeopático, não teria falecido. Mure provocou uma polêmica dentro da instituição, teve seu discurso censurado, foi impedido de publicá-lo na Revista do Instituto e logo depois excluído do número de sócios da instituição que presava pela homogeneidade entre seus membros. (MALEVAL, 2011). A disputa entre os dois modos de curar, extrapolava, assim o campo médico, refletindo em outros ambientes de sociabilidade.

Apesar das várias ofensivas contra os seus projetos, o grupo de homeopatas seguia fazendo suas publicações a fim de popularizar as teorias que adotava, como esclarece o Dr. 
Artigo

doi: $10.20396 /$ rho.v18i4.8653536

João Vicente Martins ao demonstrar apoio ao Sr. Ballá por se dispor a oferecer conselhos a cerca do Ensino Universal para os pais de família da corte:

[...] Nós que na escola de medicina homeopathica já encetámos estes trabalhos no anno passado; nós que neste anno o vamos continuar; nós, que temos conseguido que nossos discipulos se maravilhem de ter já, sem que saibão como, tão extensos conhecimentos da anatomia humana, havendo recebido tão poucas lições, e não tendo todos compreendido ou aceitado este methodo; nós nos congratulamos com o Sr. Ballá, e lhe promettemos que de nosso lado caminharemos com elle para que o methodo do ensino universal haja de ser conhecido e por todos adoptado. Já tivemos no Jornal do Commercio um manuscripto, em que pretendemos por exemplos e inducções popularisar esse methodo [...]. (JORNAL DO COMMERCIO, 1846a, p. 2).

Como explicita a publicação do Dr. João Vicente Martins, a escola homeopathica, responsável pela formação de médicos do Instituto Homeopático do Brasil, declara abertamente seu desejo de popularizar o Ensino Universal, oferecendo inclusive apoio a outras iniciativas de divulgação do mesmo. O Dr. Martins fala em nome da instituição o que comprova que o Ensino Universal era adotado pelos demais membros. Em 1846 o grupo seguia adquirindo mais adeptos, apesar de toda polêmica em torno da sua atuação na cidade do Rio de janeiro. Percebemos que já na primeira fase da divulgação do Ensino Universal, que se deu majoritariamente nas páginas do 'Jornal do Commercio', Benoît Mure conseguira atrair um bom número de simpatizantes que além de se engajarem na causa homeopática, tornaram-se também defensores dos princípios do Ensino Universal. Porém é no ano de 1847 que essa divulgação irá se tornar mais intensa.

\section{UM MÉDICO QUE NÃO É SAPATEIRO: SEGUNDA FASE DA PROPAGANDA JACOTISTA E A SCIENCIA: REVISTA SYNTHETICA DOS CONHECIMENTOS HUMANOS}

Chamamos de segunda fase da propaganda jacotista a intensificação de publicações a respeito do Ensino Universal por parte dos homeopatas aliados a Mure. Notamos que estas se deram a partir de 1847, de forma mais abundante, na revista A Sciencia: Revista Synthetica dos Conhecimentos Humanos que teve seu primeiro volume publicado em julho de 1847, e era produzida pelos próprios professores da Escola Homeopathica.

A revista abordava assuntos inerentes às diversas ciências como física, astronomia, geologia, além de assuntos relacionados à homeopatia e ao Ensino Universal de Jacotot. Notamos também que as publicações a respeito do método se tronaram mais explicativas, aprofundando a teoria de Jacotot. Para nós, isso se deu, porque pela primeira vez aquele grupo de homeopatas possuía um espaço próprio para publicar suas ideias e visões de mundo. Como nos lembra Sirinelli (2003, p. 248): “Todo grupo de intelectuais organiza-se também em torno de uma sensibilidade ideológica ou cultural comum e de afinidades mais 
difusas, mas igualmente determinantes [...]". A revista compõe-se então numa dessas estruturas de sociabilidade, e ao mesmo tempo em que são um observatório do primeiro plano dessa sociabilidade, são também um lugar importante para a análise do movimento das ideias.

Conforme o estudo de Galhardo (1928) Mure já contava em 1847 quando fundou o Instituto Panecástico do Brasil, com o poderoso auxílio de outros dois discípulos diretos de Jacotot, os senhores Eduardo Tiberghien Ackermann e A. Jernstedt. A ata da reunião em que Mure propôs a criação do Instituto foi publicada no terceiro volume da revista pertencente ao grupo. Na reunião, que ocorreu o dia 03 de maio de 1847, a proposta de Mure foi adotada por unanimidade entre os presentes. Nos estatutos da instituição podemos ler:

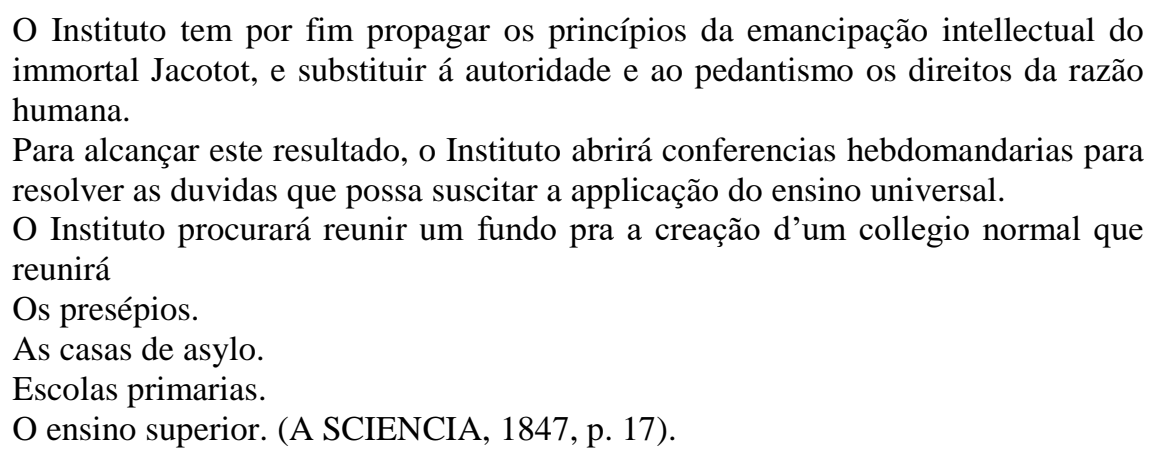

Percebemos que o grupo de médicos homeopatas pensava não só em transformar a medicina no Brasil, queria reformar as bases do conhecimento através do método de Jacotot. O grupo pensava, inclusive, na criação de um colégio normal que iria dos presépios ao Ensino Superior. Sendo a homeopatia, o primeiro ramo de ensino em que se utilizaria o método. Uma vez que para o grupo de médicos a doutrina de Hahnemann seria um verdadeiro exemplo de emancipação intelectual espontânea.

Há que se levar em conta que, para esse grupo de hoemeopatas, a teoria de Hahnemann teria surgido também pelo acaso, pois, após discordar da interpretação de um médico escocês sobre o uso de quinquina no tratamento de febres intermitentes. Hahnemann teria resolvido experimentar o medicamento em si próprio, analisando todas as reações e sintomas que a substância causava nele, para depois aplicar o medicamento nas pessoas doentes. Este experimento, até hoje polêmico, deu início às experimentações homeopáticas do médico alemão. (MÍKOLA, 2011). Talvez por isso, os professores da Escola Homeopathica do Brasil acreditassem se tratar a ciência de Hahnemann de um exemplo de aprendizagem espontânea, tal qual acreditava Jacotot, por isso também, talvez a aproximação das duas teorias por parte do grupo.

Segundo Rancière (2013) a filosofia desde Platão instituiu como mandamento para o artesão, esse que representa o homem do povo, que não se ocupasse de nada além do seu ofício, que certamente não era o de pensar. A escola, no Brasil, se constituiu Rev. HISTEDBR On-line, Campinas, v.18, n.4 [78], p.940-962, out./dez. 2018 
Artigo

doi: $10.20396 /$ rho.v18i4.8653536

historicamente como mantenedora da ordem social vigente no país desde a seu nascimento, ao abrir espaço para a entrada das classes populares sempre o fez estabelecendo duros limites, assegurando a perpetuação do velho mandamento platônico que "[...] garante a integridade e a manutenção das posições hierárquicas na escala social e intelectual." (BRETAS; CRUZ, 2015, p. 223). É exatamente essa atitude que os homeopatas do Rio de Janeiro desafiaram ao chamarem de médicos, homens que nem podiam sonhar em alisar um banco da faculdade de medicina, muito menos merecer o seu diploma; não por incapacidade, mas por conta de uma forte determinação social. O ensino escolar, assim baseado na desigualdade das inteligências é somente mais um entre os mecanismos de repressão de que fala Ribeiro (1975), pois corrobora para que as camadas oprimidas aceitem o seu destino como natural e desejável. Aquele que nasceu ferreiro, não tente ser doutor.

No número 5 da Revista 'Sciencia', Mure publicou um plano de estudos para a criação de uma universidade nacional e dedico-o aos legisladores do Brasil, fazendo uma exposição detalhada do seu projeto, admitindo, entretanto, ter poucas esperanças de vê-lo adotado pelo país, que provavelmente o substituiria por alguma imitação das universidades alemãs, para o intelectual, ainda repletas do espírito da Idade Média. Mure inicia sua explicação chamando atenção para a dependência do Brasil com relação ao velho continente europeu. E declarando que enquanto seus estadistas continuassem mendigando a Europa modelos de instituições que não estariam em harmonia "[...] nem com o seu clima, nem com seus costumes, nem com sua civilização [...]” (A SCIENCIA, nov de 1847, p. 2) o Brasil estaria deixando de representar seu próprio papel nos destinos da humanidade. Mure falava de algo que já foi apontado por muitos estudiosos da história do Brasil, a inautenticidade da sua cultura.

Como destaca mais uma vez Ribeiro (1975), durante a maior parte da história colonial do Brasil não se encontra uma camada erudita que seja a expressão da criatividade de seu povo. Mesmo depois da independência proclamada, mas para Mure, não efetivada; a criatividade cultural dessa camada erudita continuou atada aos gestos do velho contexto, afinal o Brasil continuou preservando os traços estruturais da velha sociedade, "[...] escravidão, latifúndio, monocultura.” (FERREIRA JUNIORR, 2010, p. 19). Dentro desse contexto, não se exprimia uma cultura própria, mas sempre dependente de padrões culturais alheios, primeiro da Europa, depois dos Estados Unidos.

O intelectual categorizou o ensino em dois ramos gerais, conforme a divisão dos conhecimentos humanos. O primeiro ramo correspondia às ciências físicas ou de observação exterior, já o segundo, equivaleria às ciências psicológicas ou da inteligência refletida sobre si mesma. Mure sugeria que os dois tipos de estudo se dessem de forma paralela, sendo as manhãs consagradas ao primeiro e a tarde ao segundo. A respeito dos conteúdos das duas ciências, explica ele: 


\begin{abstract}
As sciencias de observação forão classificadas segundo a ordem mais natural, e ao mesmo mais logica, principiando pelos objectos os mais sensiveis e os mais proprios a despertar a curiosidade, pelos infinitamente grandes da astronomia, e acabando pelos cálculos moleculares e os infinitamente pequenos da chimica.

As sciencias psychologicas, na sua verdadeira essencia, não são outra cousa senão a formação de ideias abstractas pela palavra. As mathematicas são a mais perfeita das linguas e a chave de todas as sciencias.

Ao estudo das línguas juntamos o estudo da historia a qual é-lhe intimamente colligada, e para tirar dobrado proveito dos seus trabalhos julgamos que o ensino da história deveria ser feito em linguas estrangeiras, para obrigar os alunos ao seu estudo. (A SCIENCIA, 1847, p. 2).
\end{abstract}

Quanto ao método de ensino a ser empregado, Mure defende o uso do método analítico de Bacon $^{4}$ para a ciência e, também o de Jacotot aplicado a pedagogia, alegando que com essa organização se acabaria com o desânimo que atingia os alunos. Mure salienta que além dos estudos pertencentes aos dois ramos do conhecimento humano, algumas horas do dia seriam destinadas a trabalhos efetivos de artes e de agricultura, que poderia ser "[...] a cultura de jardim nos dias de bom tempo, a aprendizagem de uma profissão, como a typographia, a lithographia, a esculptura, e outras occupações uteis." (A SCIENCIA, 1847, p. 3). Para o homeopata, essas seriam recreações mais agradáveis aos alunos em lugar das carreiras e os gritos desordenados que eram o único divertimento das crianças. Mure está provavelmente, se referindo ao método de ensino misto, que perdurou no Brasil desde a década de 30 até a última década do século XIX, quando se estabeleceu o método simultâneo. (FARIA FILHO, 2011).

No que diz respeito à organização das etapas de ensino, Mure as dividiu em: Presépios; Casas de asilo; Escolas primárias e; Ensino superior.

Os presepios, esta instituição social que está espalhado por toda a Europa, é o primeiro passo dado para preparar á sociedade homens uteis e razoaveis. Inutil é aqui elogiar estes estabelecimentos, cujas vantagens são bastante conhecidas. $\mathrm{O}$ nosso assombro é que elles ainda não existem, nem em esperança, no paiz que mais delles carece, no Brasil. Diremos a mesma cousa das salas de aylo. (A SCIENCIA, 1847, p. 3).

Mure, se referia aqui ao âmbito da educação infantil, que nem ao menos era pensada naquele momento, no Brasil o termo jardim de infância só seria mencionado em lei do Município da Corte, em 1879. Já a criação de creches, cujo termo se origina do francês creche que equivale a presépio, seria registrada apenas em 1899. (FILIPIM; ROSSI; RODRIGUES, 2017). As salas de asilo, assim como a creche eram, na França, etapas preparatórias para a escolarização:

Na França, lugar de origem da palavra creche, esta instituição recebia crianças de 0 a 2 anos de idade. Quando não era mais possível permanecer na creche em razão da idade, a criança ia para as salas de asilo, que se destinavam às crianças de 3 a 6 anos de idade. Com o passar do tempo, a creche e as salas de asilo se tornaram etapas que antecediam a escolarização, embora isso não conseguisse 
abranger toda a população infantil. Muitas escolas (que mais tarde receberiam o nome de escolas maternais) surgiram como aperfeiçoamento das salas de asilo francesas [...]. (LOPES; MENDES; FARIA FILHO, 2000, p. 19).

Mure destaca ainda, o papel das escolas primárias mútuas, que já haviam se estabelecido desde a lei de 15 de novembro de 1827. (FARIA FILHO, 2011). Para Mure, essas escolas só não estariam sendo eficazes por receberem meninos já “estragados" pela "falsa" educação da família individual e por adotarem o método sintético, aquele em que se aprende a ler da parte para o todo. O intelectual assim sentencia: "No dia em que as escolas mutuas se recrutarem nos presepios e nas salas de asylo, no dia em que o methodo Jacotot fôr nellas admitido, nascerão nellas os maiores prodígios.” (A SCIENCIA, 1847, p. 3).

Depois que os alunos tivessem concluído esses estudos em comum, por volta dos 16 ou 17 anos, deveriam escolher uma profissão. Mure sugere a divisão do Ensino Superior em oito Escolas de aplicação ou Faculdades:

\footnotetext{
Uma de teologia para os estudos religiosos, única base da sociedade civil. Uma de política; para formar jurisconsultos, diplomatas e administradores, entre os quaes deveria o governo escolher a maior parte dos seus empregados, atalhando assim o desenvolvimento da corrupção, que parece uma chaga inherente ao governo representativo.

Uma de pedagogia ou de phiosophia panecastica para estudar o methodo penecastico, e analysar os processos os mais vantajosos para a sua applicação.

Uma de anthropologia, abraçando a sciencia do homem e a medicina, que não é senão um dos seus ramos, cada vez menos importante depois que a adopção geral da homeopathia tiver reduzido as molestias a um numero insignificante. Uma de agricultura, que comprehenderá as sciencias applicadas a cultura do solo, á meteorologia, á criação dos animaes; á arte veterinaria. O estado deve a uma profissão tão respeitavel e tão util de eleva-la ao nivel das outras que tratão quase unicamente da distribuição e do emprego das riquezas que ella arranca do seio do nosso globo.

Uma das artes, ou escola polytechnica, abraçando as artes, a industria, a fabricação dos productos chinicos. Uma escola de navegação. Emfim, uma escola militar [...]. (A SCIENCIA, 1847, p. 3).
}

Mure finaliza a sua exposição fazendo uma crítica as academias profissionais, segundo ele, instituições que deveriam cuidar dos progressos das ciências, mas se ocupavam, ao contrário, de tolhê-los, tornando-se corporações mais nocivas do que úteis a sociedade. Mure, propunha que estas fossem ocupadas por todos os profissionais formados nas escolas superiores, dentre estes, sairia uma comissão anual de 400 membros de cada faculdade, que formaria o instituto nacional de ciências. Percebemos que o homeopata pretendia a união de todas as ciências, só assim, em sua visão, o Brasil estabeleceria seu poder político e intelectual.

Vemos na iniciativa de Mure, ao propor um projeto de universidade baseando-se no método de Jacotot, uma tentativa de institucionalizar o Ensino Universal, esse ponto constitui uma diferença entre as ideias de Mure e seu mestre, já que segundo Rancière 
Artigo

doi: $10.20396 /$ rho.v18i4.8653536

(2013, p. 143) o Ensino Universal não poderia ser institucionalizado sem que se deturpassem seus princípios, não poderia "especializar-se na produção de uma categoria determinada de atores sociais". E esse era, para Rancière o desejo de Jacotot, pois prender tal método a uma instituição seria matá-lo; tudo o que se poderia fazer pelo método de Jacotot, uma autoridade política, seria proteger a sua livre circulação entre os indivíduos. Nas palavras do autor:

[...] Jacotot foi o único igualitário a perceber que a representação e a institucionalização do progresso acarreta a renúncia à aventura intelectual e moral da igualdade e que a instrução pública era o trabalho de luto da emancipação. Um saber dessa ordem provoca uma horrorosa solidão. Jacotot acostumou-se a essa solidão [...]. (RANCIÈRE, 2013, p. 184).

É certo, como ressalta Sirinelli (2003), que um intelectual se define sempre por referência a outro intelectual de quem adquire uma herança, porém é certo também para o autor que, na distância temporal que se estabelece entre o acontecimento fundador e a gestação das suas repercussões, ocorre, na geração herdeira à fusão entre o que inato e o que é adquirido. Ficamos então com uma dúvida no que se refere a apropriação do Ensino Universal de Jacotot por Benoît Mure. Desconheceria Mure, o fato de que o Método não poderia ser jamais institucionalizado? Ou acreditou, ele, ser possível fazê-lo no Brasil? Não saberemos dar respostas a essas questões, no momento.

O que pudemos notar é que, o grupo criado por Mure não deixou de tecer duras críticas às universidades e academias brasileiras da época, qualificando-as como obstáculos ao progresso livre das inteligências e, acusando-as de recorrerem as forças armadas dos poderes constituídos para manter seu status-quo, uma vez que não conseguiam mantê-lo pelo seu próprio mérito. O grupo estaria se referindo a criação de leis que por vezes chegavam a Câmara e ao Congresso e que direta ou indiretamente propunham a extinção da homeopatia. (JANOT, 1999). E defendiam, em seus artigos, a liberdade de exercício não só da homeopatia, mas de todas as ciências no Brasil.

Durante os dois anos de circulação da revista 'A Sciencia: Revista Synthetica dos Conhecimentos Humanos' os homeopatas publicaram artigos em que defenderam a adoção do Ensino Universal ou teceram explicações a respeito da experiência e máximas jacotianas. Esses artigos foram publicados pelos professores Benoît Mure, João Vicente Martins e E. T. Ackermann. Mas, ao que parece o Ensino Universal era utilizado por todos, alunos e professores da Escola de Homeopathia, pelo menos é o que declara o Dr. DuqueEstrada, ao escrever um texto no 'Jornal da Academia Medica-Homeopathica do Brasil' em 1848, em que critica o uso do Método Jacotot:

[...] Tudo pode ser neste mundo... os annos do Sr. Mure são contados por outra maneira, que não a vulgar: pode mesmo existir a regularidade de estudos dando cada lente duas ou tres lições durante o anno, e ahi então o Sr. Cochrane que fez 2 ou 3 lições da materia que professava, o Sr. Bento Martins que fez o seu curso com uma só lição \&c... e os Srs. Duarte Moreira, Moura e Figueiredo que digão 


\begin{abstract}
quantos fizeram. Verdade é que bastaria cada lente dizer do alto de sua cadeira está aberto o curso de Chymica, o curso de tal, de tal \&c., porque depois os mesmos alunos segundo o methodo de Jacotot farião o resto. $\mathrm{E}^{\prime}$ um methodo maravilhoso este de Jacotot, porêm desgraçadamente estas maravilhas só tem logar neste Brasil! (JORNAL DA ACADEMIA MEDICA-HOMEOPATHICA DO BRASIL 1848, p. 20-21).
\end{abstract}

O Dr. Duque Estrada deixa explícito através da sua crítica que o método Jacotot era utilizado por muitos lentes da Escola Homeopathia, reforçando a influencia de Mure, que convenceu estes médicos não só a abraçarem a homeopatia, como a usarem o Ensino Universal como método para a sua instrução. Não sabemos se o Instituto Panecastico do Brasil, fundado pelo grupo, chegou a abrir suas portas algum dia. Porém, a intenção de criá-lo e a divulgação do método do Ensino Universal, está para nós, e esperamos que o esteja também para o nosso leitor, comprovadamente explícita.

\title{
A PARTIDA DE MURE
}

Mure partiu do Brasil no dia 13 de abril de 1848, "[...] sete anos, quatro meses e vinte e três dias depois de sua chegada, a bordo da barca francesa - Girande." (DINIZ, 2008, p. 34). O intelectual publica sua despedida do país, tanto no 'Jornal do Commercio', como na revista 'A Sciencia', alegando precisar cuidar de sua saúde, deteriorada por sete anos de trabalhos não interrompidos e também por julgar que seus trabalhos não seriam mais tão necessários. Afirma que compreende também que poderia ajudar a causa homeopática de outra maneira, sem precisar expor tanto sua saúde.

Mure declara ter o desejo de colher os materiais produzidos por ele durante o tempo em que residiu no Brasil e publicar na Europa, a fim de tornar conhecidos os progressos da doutrina de Hahnemann no Brasil. E o fez quando em 1849, na França, a obra 'Patogenesia Brasileira e Doutrina da Escola Homeopática do Rio de Janeiro' foi publicada contendo a análise de "[...] 36 substancias novas, bem como a teoria das doses e desenhos de máquinas farmacêuticas." (JANOT, 1999).

Mure acreditava que o Brasil ocupava a maior posição na história da homeopatia, naquele momento e alegou em sua despedida, que o sucesso do seu empreendimento no novo mundo, se deveu ao trinfo do gênio esclarecido do povo brasileiro, a integridade dos magistrados. Não deixando de agradecer o zelo dos lentes da Escola Homeopathica e a dedicação dos alunos. Prestou ainda um agradecimento especial ao seu amigo Dr. João Vicente Martins, a quem deixava a incumbência de continuar insistindo na regulamentação da homeopatia no Brasil.

Na ocasião, João Vicente Martins também agradeceu e se despediu do seu mestre e amigo, incentivando-o a continuar a sua missão a favor da homeopatia sempre para o bem dos homens, sem pensar na ingratidão e nem recuar ante aos obstáculos. Martins revela nas 
palavras de incentivo ao amigo, o caráter sacerdócio com que esses intelectuais revestiram as causas que defenderam. Martins agradece a confiança, e usando máximas jacotistas, assegura ao amigo:

[...] entretanto ide seguro de que, se acaso me faltarem os talentos, não me hade faltar a coragem, nem tão pouco a boa vontade de ser util aos meus semelhantes: e como a boa vontade alcança tudo o que é licito, e como só pela força da vontade póde qualquer homem ensinar aos outros, até mesmo tudo aquillo que elle ignora; talvez que a minha vontade possa bem supprir a falta de talento [...]. (A SCIENCIA, 1848, p. 5)

Mure, assim como João Vicente Martins, acreditou que um homem pode tudo o que quiser, se tiver vontade e constância no que faz, e nesse ponto da história da homeopatia feita no Brasil, percebemos a marca de Jacotot. De certo, os homeopatas não conseguiram mudar a ordem social contra a qual combateram, mas escreveram no Brasil do século XIX uma experiência de emancipação intelectual a sua maneira.

\section{CONSIDERAÇÕES FINAIS}

O século XIX parecia ser o século dos possíveis, e por isso, para nós existe em sua história algo de encantador, uma vez que no nosso século, já não nos parece tão simples acreditar na possibilidade de construir uma sociedade baseada na igualdade, quanto era aos nossos antepassados. É claro que continuamos lutando por nossas pequenas e cada vez mais individuais causas; mas, pensar numa luta que leve a transformação geral é cada vez mais difícil. Já no século XIX isso não soava tão absurdo. Jacotot e Benoît Mure, nasceram, viveram, atuaram e morreram no século dos possíveis e, carregavam em si toda a energia engendrada no que o possível pode significar.

Foi possível constatar que durante sua passagem pelo Brasil, Benôit Mure, chegou ao país como um total desconhecido, mas disposto a colocar em prática as teorias de seus mestres. Fourrrier, com a criação do Falanstérios; Hahnemann com a homeopatia e Jacotot, com os princípios do Ensino Universal. Mure, conseguiu dentro de pouco tempo, atrair para si muitos simpatizantes, às vezes chamados pelos opositores de discípulos seus. Entre esses, figuras de renome na sociedade carioca. Atuou como um intelectual despertador (SIRINELLI, 2003) e conseguiu agregar um grupo vigilante e fervorosamente partidário as teorias por ele apresentadas.

Benoit Mure, atuou de diferentes formas a favor da divulgação do Ensino Universal, por isso, dividimos suas ações em duas fases, sendo que na primeira, por ser um recém chegado, apesar de ter angariado admiradores desde o início de sua estadia no Brasil, atuou por meio de divulgações de convites e oferecimento de explicações sobre a doutrina de Jacotot, que se concentraram, especialmente, nas páginas do 'Jornal do Commercio' do Rio de Janeiro. Na segunda fase, ocorreu a intensificação de suas ações 
com a criação da revista A 'Sciencia: Revista Synthetica dos Conhecimentos Humanos', a fundação do Instituto Panecástico do Brasil', além da aplicação do método na Escola Homeoptathica.

A propaganda do Ensino Universal realizada por Mure, e depois por seus partidários, esteve fortemente marcada pela prática médica homeopática e socialista desse intelectual, que conseguia harmonizar teorias de diferentes campos do saber humano, acreditando que através da aplicação desses conhecimentos seria possível a criação de uma comunidade de homens emancipados, sadios e venturosos. Mure sonhou um sonho grande e belo muito característico dos utopistas do século XIX, sonhou-o não só por meio de suas palavras, mas também por ações políticas efetivas. Aplicou sua medicina aos cuidados de escravos e indigentes, admitiu em sua escola filhos de trabalhadores do povo, conferindolhes títulos de doutores e movimentou a estrutura social da época.

\section{REFERÊNCIAS}

A SCIENCIA: Revista Synthetica dos Conhecimentos Humanos. Rio de Janeiro, [18471848], Semestral.

BARRA, S. H. da. S. A Cidade corte: o Rio de Janeiro no início do século XIX. COLÓQUIO INTERNACIONAL DE HISTÓRIA CULTURAL DA CIDADE, 1., 2015, Porto Alegre. Anais... Porto Alegre, 2015. p. 791-805. Disponível em: <http://www.ufrgs. br/gthistoriaculturalrs/55CDSergiohamiltondasilvaBarra.pdf>. Acesso em: 14 dez. 2017.

BRETAS, S. A.; CRUZ, C. S. O mestre e o aprendiz como iguais: a potência da vontade e da inteligência humana em Rancière. In: Revista HISTEDBR On-line, Campinas, n. 63, p. 210-232, jun. 2015. Disponível em: <https://periodicos.sbu.unicamp.br/ojs/index.php /histedbr/article/view/8641179>. Acesso em: 10 dez. 2015.

BURMEISTER, H. Viagem ao Brasil através das províncias do Rio de Janeiro e Minas Gerais: visando especialmente a história natural dos distritos auridiamentíferos. Tradução: Manoel Salvaterra e Hubert Schoenfeldt; nota bio-bibliográfica Augusto Meyer. Belo Horizonte: Itatiaia; São Paulo: Universidade de São Paulo, 1980.

DINIZ, M. F. P. Benoît-Jules Mure no Brasil: 1840-1848. 2008. Tese (Doutorado) Instituto de Cultura e Escola e Homeopatia, 2008. Disponível em: <http://bases.bireme.br/ cgibin/wxislind.exe/iah/online/?IsisScript=iah/iah.xis\&src=google\&base=HomeoIndex\&la ng=p\&nextAction=lnk\&exprSearch=11122\&indexSearch=ID>. Acesso em: 15. jun. 2016.

FARIA FILHO, L. M. Instrução elementar no século XIX. In: LOPES, E. M. T.; FARIA FILHO, L. M.; VEIGA, C. G. (Org.). 500 anos de educação no Brasil. 5. ed. Belo Horizonte: Autentica, 2011. p. 135-150. 
Artigo

doi: $10.20396 /$ rho.v18i4.8653536

FERREIRA JUNIOR, A. História da educação Brasileira: da colônia ao século XX. São Carlos: EdUFSCar, 2010. Disponível em: <https://www.researchgate.net/profile/Amarilio_ Ferreira_Jr/publication/270903884_Historia_da_Educacao_Brasileira_da_Colonia_ao_sec ulo_XX/links/554b5a280cf21ed21359275d/Historia-da-Educacao-Brasileira-da-Coloniaao-seculo-XX.pdf>. Acesso em: 14 dez. 2017.

FILIPIM, P. V. de. S.; ROSSI, E. R.; RODRIGUES, E. História da institucionalização da educação infantil: dos espaços de assistência à obrigatoriedade de ensino (1875-2013).

Rev. HISTEDBR On-line, Campinas, v. 17, n. 2 [72], p. 605-620, abr./jun. 2017. Disponível em: <https://periodicos.sbu.unicamp.br/ojs/index.php/histedbr/article/ download/.../16934>. Acesso em: 14dez. 2017.

GALHARDO, J. E. R. História da homeopatia no Brasil. In: GALHARDO, J. E.R. (Org.). Livro do $1^{\circ}$ Congresso Brasileiro de Homeopatia. Rio de Janeiro, 1928. p. 271-1016. (BN). Disponível em: <http://www.brasiliana.usp.br/handle/1918/06003100\#page/414/ mode/1up>. Acesso em: 15 jul. 2016.

JANOT, C. Benoît Mure (1809-1858). 1936 (Biografia) In: MURE, B. J. (Org.).

Patogenesia brasileira. Tradução: Maria Silvia Mourão Netto. São Paulo: Rocca. 1999. p. XI-XXI.

JORNAL DA ACADEMIA MEDICA-HOMEOPATHICA DO BRASIL. Rio de Janeiro, n. 01 , jan. 1848.

JORNAL DO COMMERCIO. Rio de Janeiro, Rio de Janeiro, 2 out. 1846a.

JORNAL DO COMMERCIO. Rio de Janeiro, Rio de Janeiro, 7 dez. de 1840a.

JORNAL DO COMMERCIO. Rio de Janeiro, Rio de Janeiro, 8 jul. $1846 \mathrm{~b}$.

JORNAL DO COMMERCIO. Rio de Janeiro, Rio de Janeiro, 17 dez. 1840 b.

JORNAL DO COMMERCIO. Rio de Janeiro, Rio de Janeiro, 20 set. 1841.

JORNAL DO COMMERCIO. Rio de Janeiro, Rio de Janeiro, n. 86, 1 abr. 1848.

JORNAL DO COMMERCIO. Rio de Janeiro, Rio de Janeiro, n. 274, 5 out. 1846c.

LIMA, L. M. de. Os letrados e a imprensa: um perfil do intelectual brasileiro oitocentista. In: ENCONTRO REGIONAL DE HISTÓRIA: PODER, VIOLÊNCIA E EXCLUSÃO, 19., 2008, São Paulo. Anais... São Paulo: ANPUH/SP-USP, 2008. 12 p. Disponível em: < <http://www.anpuhsp.org.br/sp/downloads/CD\%20XIX/PDF/Autores \%20e\%20Artigos/Lilian\%20Martins\%20de\%20Lima.pdf >. Acesso em: 14 dez. 2017.

LOPES, K. R.; MENDES, P. R.; FARIA, V. L. B. de. (Org.). Coleção PROINFANTIL. Modulo 1. Unidade 3. Brasília: MEC; Secretaria de Educação Básica; Secretaria de 
Artigo

doi: $10.20396 /$ rho.v18i4.8653536

Educação a Distância, 2005. (Livro de estudo, v. 2). Disponível em: <http://portaldo professor.mec.gov.br/storage/materiais/0000012723.pdf>. Acesso em: 14dez. 2017.

MALEVAL, I. T. Bento Mure e a querela médica nas páginas da Revista do Instituto Histórico e Geográfico brasileiro de 1847. Revista de Teoria da História, v. 6, n. 2, p. 150-177, 2011. Disponível em: < https://www.academia.edu/23238161/BENTO_MURE_ E_A_QUERELA_M\%C3\%89DICA_NAS_P\%C3\%81GINAS_DA_REVISTA_DO_INST ITUTO_HIST\%C3\%93RICO_E_GEOGR\%C3\%81FICO_BRASILEIRO_DE_1847>. Acesso em: 15 jun. 2016.

MÍKOLA, N. A inserção da homeopatia no Brasil e o espiritismo como estratégia de legitimação (1860-1890). Revista Brasileira de História das Religiões, Maringá-PR, n, v. 9, 2011. Disponível em: <http://www.dhi.uem.br/gtreligiao/pdf8/ST1/003\%20-\%20Nadia $\% 20$ Mikola.pdf>. Acesso em: 15 jun. 2016.

PEREIRA, M. E. M. A indução para o conhecimento e o conhecimento para a vida prática: Francis Bacon. In: ANDERY, M. A. et al. (Org.) Para compreender a ciência: uma perspectiva histórica. 6. ed. rev. ampl. Rio de Janeiro: Espaço e Tempo, EDUC, 1996. p. 193-200.

RANCIÈRE, J. O mestre ignorante: cinco lições sobre a emancipação intelectual. Tradução: Lílian do Valle. 3. ed. 2. Reip. Belo Horizonte: Autêntica, 2013.

RIBEIRO, D. Estudos da antropologia da civilização, IV: os brasileiros, livro I. Teoria do Brasil. 2. ed. Rio de Janeiro: Civilização Brasileira, 1975.

SIRINELLI, J. Os intelectuais. In: RÉMOND, R. (Org.). Por uma história política.

Tradução: Dora Rocha. 2. ed. Rio de Janeiro: FGV, 2003. p. 231-269.

Notas

\footnotetext{
${ }^{1}$ Professora Mestre em Educação pelo Programa de Pós-Graduação em Educação da Universidade Federal de Sergipe. E-mail: crislainescruz@gmail.com

2 Professora Dra. do Departamento de Educação e do Programa de Pós-Graduação em Educação da Universidade Federal de Sergipe. E-mail: s-bretas@ hotmail.com

${ }^{3}$ Dom Afonso Pedro (1845-1847) morreu aos dois anos de idade. (MALEVAL, 2011).

${ }^{4}$ Francis Bacon (1561 - 1626) é considerado o pai do empirismo moderno por ter formulado os fundamentos dos métodos de análise e pesquisa da ciência moderna. Defendia a aplicação da ciência à indústria, a serviço do progresso. Buscou formular um método para o conhecimento da natureza que pudesse ser definido como científico e que pudesse ser repetido. (PEREIRA, 1996).
}

Submetido em: 30/09/2018

Aprovado em: 15/12/2018

Publicado em: 21/12/2018 